\title{
WISP-I overexpression upregulates cell proliferation in human salivary gland carcinomas via regulating MMP-2 expression
}

This article was published in the following Dove Press journal:

OncoTargets and Therapy

21 October 2016

Number of times this article has been viewed

Fu-Jun Li

Xin-Juan Wang

Xiao-Li Zhou

Department of Stomatology, The First Affiliated Hospital of Henan University of Science and Technology, Luoyang, People's Republic of China
Correspondence: Fu-Jun Li

Department of Stomatology, The First Affiliated Hospital of Henan University of Science and Technology, No 24, Jinghua Road, Jianxi District, Luoyang 47I003, Henan Province, People's Republic of

China

Tel +8637964830803

Email forjunelee@I63.com
Background: WISP-1 is a member of the CCN family of growth factors and has been reported to play an important role in tumorigenesis by triggering downstream events via integrin signaling. However, little is known about the role of WISP-1 in proliferation of salivary gland carcinoma (SGC) cells.

Methods: In this study, we investigated the WISP-1 expression in SGC tissues via immunohistochemical staining, Western blotting assay, and real-time quantitative polymerase chain reaction method, and then evaluated the regulatory role of WISP-1 in the growth of SGC A-253 cells. In addition, the role of MMP-2 in the WISP-1-mediated growth regulation was also investigated.

Results: It was demonstrated that the WISP-1 expression was upregulated at both mRNA and protein levels in 15 of 21 SGC tumor tissues, compared to the non-tumor tissues (five of 21), associated with the lymph node dissection and bone invasion. The in vitro CCK-8 assay and colony-forming assay demonstrated that the exogenous WISP-1 treatment or the WISP-1 overexpression promoted the growth of A-253 cells. In addition, we confirmed that the WISP-1 overexpression upregulated the MMP-2 expression in A-253 cells with the gain-of-function and loss-of-function strategies, and that the MMP-2 knockdown attenuated the WISP-1-mediated growth promotion of A-253 cells.

Conclusion: We found that WISP-1 was overexpressed in the human SGCs, and the WISP-1 overexpression promoted the salivary gland cell proliferation via upregulating MMP-2 expression. Our study recognized the oncogenic role of WISP-1 in human SGCs, which could serve as a potential target for anticancer therapy.

Keywords: WISP-1, SGCs, proliferation, MMP-2

\section{Background}

The incidence of head and neck carcinomas, including salivary gland carcinomas (SGCs), is increasing worldwide, while the survival rate of patients with head and neck carcinoma has not substantially improved over the last 2 decades $^{1}$ due to the heterogeneity of the carcinoma. ${ }^{2}$ Thus, novel therapies are urgently needed to supplement the treatment currently available for SGCs. SGCs account for $\sim 3 \%-6 \%$ of all head and neck malignancies. ${ }^{3,4}$ In recent years, multiple molecular markers, such as PTTG, CDKN2A, TP53, and EGFR, have been found to be prognostic of SGCs..$^{5-8}$ In particular, the EGFR positivity has been recognized in $\sim 82 \%-91 \%$ of SGC samples. ${ }^{6,9}$

The CCN family of growth factors derived their name from the acronym of the first three members of the family: cyr61, CTGF, and NOV. ${ }^{10}$ They share properties including stimulation of cell proliferation, migration, adhesion, and extracellular matrix (ECM) 
formation, as well as angiogenesis and tumorigenesis. ${ }^{11,12}$ WISP-1, also known as CCN4, is a cysteine-rich, secreted matricellular protein. ${ }^{13}$ WISP-1 is a downstream target of Wnt- 1 and $\beta$-catenin. ${ }^{14}$ Recently, the deregulation of WISP-1 has been indicated to result in various pathologies including osteoarthritis, ${ }^{15}$ fibrosis, ${ }^{16}$ and cancers. ${ }^{17,18}$ However, the exact role of WISP-1 in tumorigenesis is not clear. Although the WISP-1 overexpression correlates with metastasis of these cancers and hence poor overall survival, it is not clear whether the oncogenic molecule contributes to tumorigenesis of SGCs.

In the present study, we evaluated the WISP-1 overexpression in the human SGC specimens by immunohistochemical analysis, Western blot analysis, and real-time quantitative polymerase chain reaction (RT-qPCR). To investigate the regulatory role of WISP-1 in the proliferation of SGC cells, we overexpressed WISP-1 in A-253 cells or treated A-253 cells with exogenous WISP-1, and then investigated the influence of WISP-1 on the proliferation of A-253 cells. In some specimens, we knocked down WISP-1 with WISP-1specific siRNA, and reevaluated the proliferation of A-253 cells. In addition, the regulation by WISP-1 of the expression of MMP-2 in A-253 cells was investigated. It was implied that WISP-1 plays a regulatory role in the proliferation of salivary gland cells, and could serve as a potential target for anticancer therapy.

\section{Materials and methods SGC specimens, A-253 cell culture, and treatment}

Our study was approved by the Medical Ethics Committee of the First Affiliated Hospital of Henan University of Science and Technology. Twenty-one human SGC specimens and 21 control salivary gland specimens (as control) were collected by surgical resection, before any radiotherapy or chemotherapy, from SGC patients or from salivary gland adenoma patients. Each patient provided written informed consent for the use of specimens. Clinicopathological data of patients were recorded prospectively, including age, sex, tumor size, and other items (Table 1). Human salivary gland A-253 cell line was purchased from American Type Culture Collection (ATCC) (Manassas, VA, USA) and was cultured in McCoy's 5a Medium Modified (Thermo Fisher Scientific, Waltham, MA, USA), which was supplemented with $10 \%$ fetal bovine serum (Thermo Fisher Scientific), at $37^{\circ} \mathrm{C}$ in a humidified incubator with $5 \% \mathrm{CO}_{2}$. Human recombinant WISP-1 (R\&D Systems China, Shanghai, People's Republic of China) was dissolved in McCoy's 5a Medium Modified
Table I Association of WISP-I mRNA level with the clinicopathologic characteristics of patients with salivary gland carcinoma

\begin{tabular}{|c|c|c|c|}
\hline \multirow{2}{*}{$\begin{array}{l}\text { Clinicopathologic } \\
\text { characteristics }\end{array}$} & \multirow[t]{2}{*}{ Cases $(\mathbf{N})$} & \multicolumn{2}{|c|}{ Expression of WISP-I } \\
\hline & & mRNA level & $P$-value \\
\hline Age (years) & & & 0.4365 \\
\hline$\leq 55$ & 12 & $1.7642 \pm 0.2104$ & \\
\hline$>55$ & 9 & $1.6094 \pm 0.1836$ & \\
\hline Sex & & & 0.6217 \\
\hline Male & 10 & $1.7856 \pm 0.203 \mid$ & \\
\hline Female & II & $1.6184 \pm 0.1853$ & \\
\hline Tumor size $(\mathrm{cm})$ & & & 0.1126 \\
\hline$\leq 2.5$ & 13 & $1.6178 \pm 0.1726$ & \\
\hline$>2.5$ & 8 & $1.8275 \pm 0.2132$ & \\
\hline Lymph node dissection & & & 0.0213 \\
\hline No & 14 & $1.5719 \pm 0.1705$ & \\
\hline Yes & 7 & $1.9476 \pm 0.2342$ & \\
\hline Bone invasion & & & 0.0182 \\
\hline No & 16 & $1.5928 \pm 0.1823$ & \\
\hline Yes & 5 & $2.0336 \pm 0.2417$ & \\
\hline
\end{tabular}

and was utilized at a final concentration of 0,10 , or $30 \mathrm{ng} / \mathrm{mL}$ to treat A-253 cells. To overexpress WISP-1 in A-253 cells, the wild-type human WISP-1-coding sequence was amplified and cloned into the pcDNA3.1(+) vector. The expression of WISP-1 at both mRNA and protein levels in A-253 cells was examined at $0,24,48$, or 72 hours post-transfection with the WISP-1-pcDNA3.1(+) or control Ctrl-pcDNA3.1(+) plasmids (which expressed enhanced green fluorescent protein). Lipofectamine 2000 (Thermo Fisher Scientific) was utilized to transfect plasmids into A-253 cells. To knock down WISP-1, siRNA-WISP-1 or control siRNA (siRNA-Ctrl) (GenePharma, Shanghai, People's Republic of China) was transfected with Lipofectamine RNAiMax (Thermo Fisher Scientific) into A-253 cells at a concentration of 30 or $60 \mathrm{nM}$.

\section{Immunohistochemical staining for WISP-I in SGC tissues}

Paraffin-embedded slides of SGC tissues were successively deparaffinized by heating at $55^{\circ} \mathrm{C}$, rehydrated serially with different concentrations of ethanol, and then were prepared for the antigen retrieval by heating at $98^{\circ} \mathrm{C}$ in $10 \mathrm{mM}$ sodium citrate (pH 6.0). The endogenous peroxidase activity was blocked with $0.3 \%$ hydrogen peroxide for 20 minutes. The rabbit polyclonal antibody to human WISP-1 (Cat PA529150; Thermo Fisher Scientific) was utilized to stain the WISP-1. After the incubation with the primary WISP-1 antibody at room temperature for 2 hours, the slides were incubated with goat anti-rabbit IgG-HRP (Cat sc-2004; Santa Cruz Biotechnology Inc., Santa Cruz, CA, USA) at room 
temperature for 1 hour. Then, the slides were incubated with Pierce $^{\mathrm{TM}}$ DAB Substrate Kit (Thermo Fisher Scientific) for several minutes to stain the WISP-1. Each slide was dehydrated and sealed with coverslips.

\section{RT-qPCR analysis}

mRNA from SGC tissues or from A-253 cells was isolated with the PolyAttract ${ }^{\circledR}$ mRNA Isolation Kit (Promega Corporation, Fitchburg, WI, USA) under the guidance of the kit's manual, and each mRNA sample was treated with $1 \mu \mathrm{L}$ RNasin ${ }^{\circledR}$ Plus RNase Inhibitor (Promega Corporation). mRNA samples were stored at $-80^{\circ} \mathrm{C}$ before use. RT-qPCR was performed using an iTaq ${ }^{\mathrm{TM}}$ Universal one-step RT-qPCR Kit (Bio-Rad Laboratories Inc., Hercules, CA, USA), with $\beta$-actin as an internal control. The primers for WISP-1 were 5'-CTG CAT CAG CAC ACG CTC CT-3' (forward) and 5'-TGT AGG GGA TGC AGC ACC TAT-3' (reverse), and primers for $\beta$-actin were $5^{\prime}$-GCT GCT GAC CGA GGC CCC CCT-3' (forward) and 5'-GAA GGT CTC AAA CAT GAT CT-3' (reverse). All primers were synthesized by Shanghai Sangon company (Shanghai, People's Republic of China). The WISP-1 mRNA level was calculated as the fold change compared to the internal $\beta$-actin control with the $\Delta \Delta \mathrm{Ct}$ method. ${ }^{19}$

\section{Western blot analysis}

WISP-1 protein level in tumor specimens or in A-253 cells was relatively quantified by Western blotting. The homogenized SGC specimens or cultured cells were isolated with the NE-PER ${ }^{\text {TM }}$ Nuclear and Cytoplasmic Extraction Reagents (78833; Thermo Fisher Scientific), under the guidance of the kit's manual. Each protein sample was treated with a protease inhibitor cocktail (Sigma-Aldrich, St Louis, MO, USA) and was stored at $-80^{\circ} \mathrm{C}$ before use. Electrophoresis with $12 \%$ sodium dodecyl sulfate-polyacrylamide gel was performed to separate the protein bands, which were then transferred to a polyvinylidene fluoride hydrophobic membrane (EMD Millipore, Billerica, MA, USA). The band of WISP-1 or $\beta$-actin was specifically bound by the polyclone rabbit antiWISP-1 (Abcam, Cambridge, UK) or anti- $\beta$-actin antibody (Abcam), and was subjected to binding with the peroxidaseconjugated secondary antibody (Bio-Rad Laboratories Inc.), and detected via coloration with the electrochemiluminescence detection system (Thermo Fisher Scientific).

\section{Cell proliferation and cell colony formation}

CCK-8 assay (Dojindo, Kumamoto, Japan) was performed to examine the proliferation of A-253 cells. Briefly, A-253 cells that were $\sim 85 \%$ confluent after the WISP- 1 treatment or the siRNA (siRNA-Ctrl or siRNA-MMP-2) transfection were cultured at $37^{\circ} \mathrm{C}$ in a humidified incubator with $5 \% \mathrm{CO}_{2}$ for 12,24 , or 48 hours. Then, cells were incubated with CCK-8 until visual color appeared, and their absorbance at $450 \mathrm{~nm}$ was calculated. Colony formation assay for A-253 cells was performed as follows: A-253 cells (500 per well) were incubated in 12 -well plates at $37^{\circ} \mathrm{C}$ in the presence of $5 \% \mathrm{CO}_{2}$, and were treated with 0,10 , or $30 \mathrm{ng} / \mathrm{mL}$ WISP-1, or were transfected with WISP-1-pcDNA3.1(+) or Ctrl-pcDNA3.1(+) plasmid (500 ng per well), or siRNA-Ctrl or siRNA-MMP-2 $(50 \mathrm{nM})$. Then, cells were incubated for another 48 hours, and were stained with crystal violet $(0.005 \%)$ for 20 minutes to record the colony numbers.

\section{Statistical analysis}

All data are expressed as mean \pm standard error of the mean. The difference in WISP-1 positivity between the two groups was evaluated by chi-square test. The expression of WISP-1 or MMP-2 at mRNA or protein level, or the cell number of the two groups was analyzed by Student's $t$-test. The difference in the CCK-8 assay results was analyzed using analysis of variance. A $P$-value of $\leq 0.05$ was considered statistically significant.

\section{Results \\ Overexpression of WISP-I in SGC tissues}

To recognize the role of WISP-1 in SGC, we examined the WISP-1 expression in SGC tissues. First, immunohistochemical staining was performed to analyze the WISP-1 expression in situ in SGC $(\mathrm{N}=21)$ or control salivary gland tissues $(\mathrm{N}=21)$. Figure $1 \mathrm{~A}$ and $\mathrm{B}$ demonstrates the positive staining for WISP-1 in SGC tissues (positivity =15/21), which was significantly higher than in the normal salivary gland tissues (positivity $=5 / 21)(P=0.002)$. Then, Western blotting was performed to quantify the protein level of WISP-1 in the 15 WISP-1-positive SGC specimens. As indicated in Figure 1C, the relative protein level of WISP-1 compared to $\beta$-actin was also significantly higher in the SGC group $(P<0.001$, paired-samples $t$-test; Figure 1D). Finally, we performed the RT-qPCR assay to calculate the WISP-1 mRNA level in both groups. Figure $2 \mathrm{~A}$ demonstrates that the relative mRNA level of WISP-1 in SGC specimens was $1.667 \pm 0.315(\mathrm{~N}=21)$, which was significantly higher than $1.000 \pm 0.146$ in control group $(\mathrm{N}=21)(P<0.001)$. Also, the relative mRNA level of WISP-1 was higher in five of six SGC specimens, compared to the peri-SGC specimens ( $P<0.05$ or $P<0.01$; Figure $2 \mathrm{~B})$. 
A

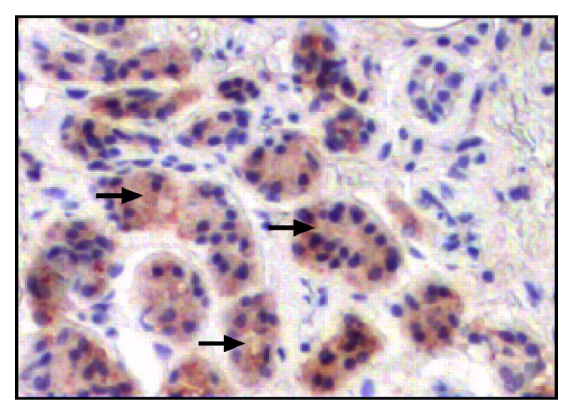

C

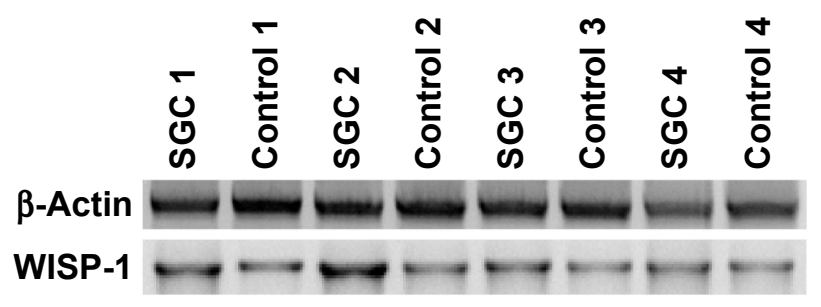

B

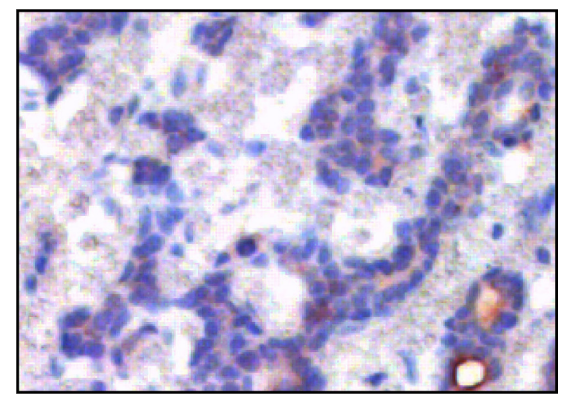

D

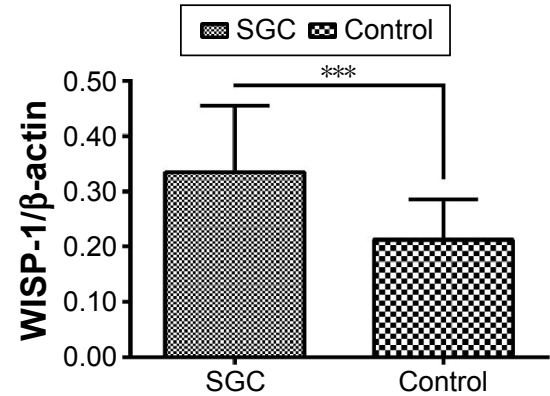

Figure I Immunohistochemical staining for WISP-I expression in human salivary gland carcinoma tissues.

Notes: Representative WISP-I staining in human salivary gland carcinoma $(\mathbf{A}, \mathrm{N}=2 \mathrm{I})$ or control salivary gland tissues $(\mathbf{B}, \mathrm{N}=2 \mathrm{I})$. (C) Representative Western blotting assay of WISP-I protein level in control or human salivary gland carcinoma tissues. (D) Relative protein level of WISP-I compared to $\beta$-actin in the control (N=I5) or human salivary gland carcinoma tissues $(\mathrm{N}=15)$. (A) and $(\mathbf{B})$ were $\times 400$ under light microscope. (A) Positive staining was indicated by the black arrows. $* * * P<0.00 \mathrm{I}$.

Abbreviation: SGC, salivary gland carcinoma.

In addition, we associated the WISP-1 mRNA level with the clinicopathologic characteristics of SGC patients. As indicated in Table 1, there was a marked association of the WISP-1 overexpression with the lymph node dissection or bone invasion $(P=0.0213$ or $P=0.0182)$. Taken together, we found that WISP-1 was overexpressed in SGC specimens.

\section{WISP-I promotes the proliferation of human salivary gland A-253 cells}

To investigate the regulatory role of WISP-1 in SGC cells, we treated A-253 cells with 0,10 , or $30 \mathrm{ng} / \mathrm{mL}$ recombinant human WISP-1, and then examined the proliferation of A-253

A
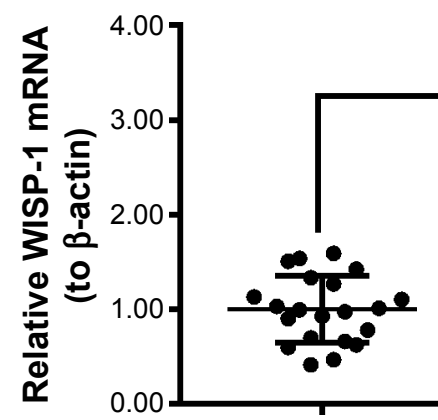

Control
$* * *$

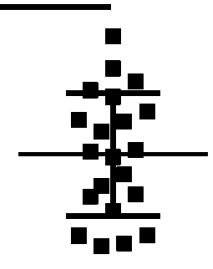

Figure 2 mRNA level of WISP-I in human salivary gland carcinoma tissues.

Notes: (A) RT-qPCR analysis of the WISP-I mRNA level in the control $(\mathrm{N}=2 \mathrm{I}$ ) or human salivary gland carcinoma $(\mathrm{N}=2 \mathrm{I})$ tissues. (B) Relative WISP-I mRNA level in the human salivary gland carcinoma $(\mathrm{N}=6)$ or peri-tumor $(\mathrm{N}=6)$ tissues. $\beta$-Actin was taken as an internal control. $* P<0.05$, $* * P<0.0 \mathrm{I}$, and $* * * P<0.00 \mathrm{I}$.

Abbreviations: RT-qPCR, real-time quantitative polymerase chain reaction; SGC, salivary gland carcinoma; ns, no significance.

cells. As indicated in Figure 3A, there was a significant difference in the growth curve of the A-253 cells after the treatment with 0,10 , or $30 \mathrm{ng} / \mathrm{mL}$ WISP-1 $(P<0.05$ or $P<0.01$ for 24 or 48 hours posttreatment, respectively). The colonyforming assay was also performed to examine the difference in the proliferation of WISP-1-treated or WISP-1-untreated A-253 cells. Results demonstrated that there were more colonies in the group of A-253 cells, which were treated with 10 or $30 \mathrm{ng} / \mathrm{mL}$ WISP-1, than in the A-253 cells not treated with WISP-1 $(P<0.01$; Figure 3B and C). Then, we overexpressed WISP-1 in A-253 cells via transfecting with the recombinant WISP-1-pcDNA3.1(+) plasmid. Figure 4A indicates that the

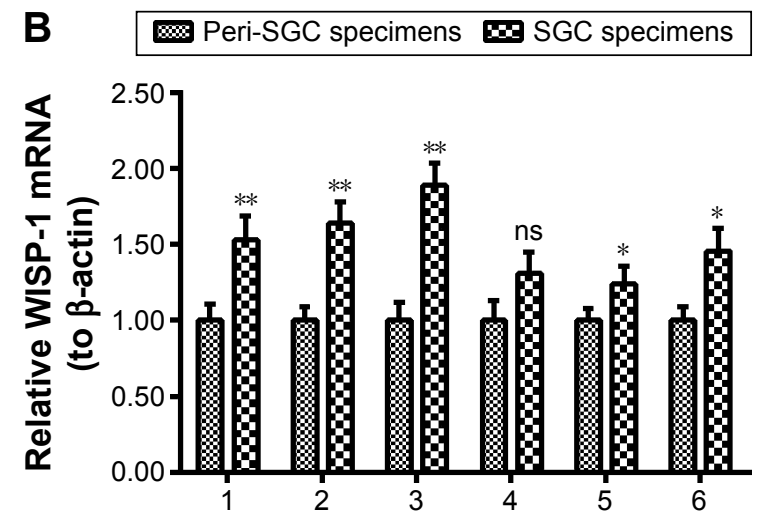




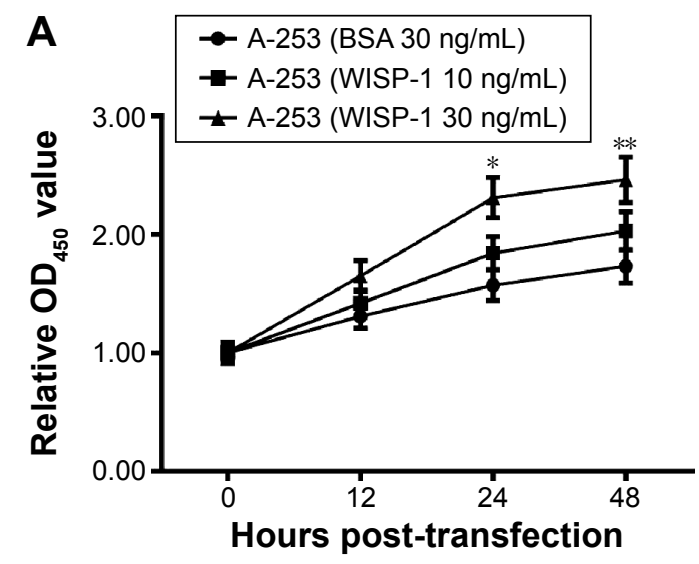

B

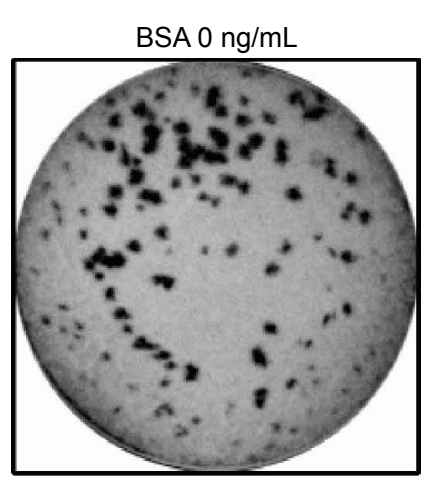

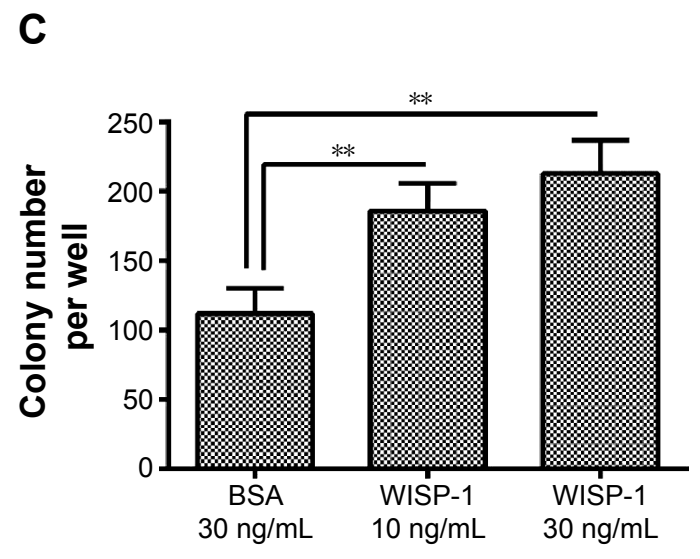

WISP-1

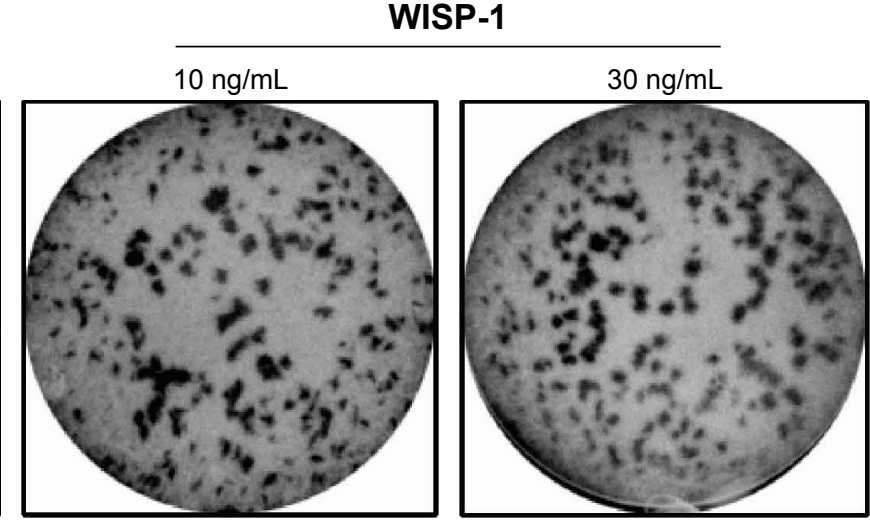

Figure 3 Exogenous recombinant human WISP-I promotes the growth of A-253 cells.

Notes: (A) CCK-8 assay for the growth curve of the A-253 cells, which were treated with 0, 10, or $30 \mathrm{ng} / \mathrm{mL}$ for $0,12,24$, or 48 hours. (B) Colony-forming assay and (C) colony counting for the A-253 cells, which were treated with 0 , 10, or $30 \mathrm{ng} / \mathrm{mL}$ for 48 hours. Results were averaged for triple independent experiments. $* P<0.05$ and $* * P<0.01$.

Abbreviations: OD, optical density; BSA, bovine serum albumin.

WISP-1 mRNA level was significantly upregulated in A-253 cells after the WISP-1-pcDNA3.1(+) transfection at 24, 48, or 72 hours $(P<0.001)$. The Western blotting result (Figure 4B) also indicated that the protein level of WISP-1 was upregulated in the WISP-1-pcDNA3.1(+)-transfected A-253 cells at 24,48 , or 72 hours $(P<0.001$; Figure $4 C)$. Moreover, the colony-forming assay also demonstrated that more colonies were formed by the A-253 cells, which were transfected with WISP-1-pcDNA3.1(+) (A-253 WISP-1 Up), than those which were transfected with the control plasmid (A-253 Ctrl Up) $(P<0.01$; Figure 4D and E). Thus, our results found the promotive role of WISP-1 in the proliferation of A-253 cells.

\section{WISP-I upregulates MMP-2 expression in A-253 cells}

WISP-1 has been indicated to promote the MMP-2 expression in various types of tumor cells. ${ }^{20,21}$ In the present study, we investigated the regulation by WISP-1 of the MMP-2 expression in A-253 (WISP-1 Up) cells. Figure 5A demonstrates that the MMP-2 mRNA was markedly higher in the A-253 cells transfected with the WISP-1-pcDNA3.1(+) at 24,48 , or 72 hours $(P<0.05$ or $P<0.01)$. The Western blotting assay also indicated that the protein level of MMP-2 was significantly higher in the A-253 (WISP-1 Up) cells than in the A-253 (Ctrl Up) cells, at 24, 48, or 72 hours post-transfection $(P<0.01$; Figure $5 \mathrm{~B})$. Then, we knocked down WISP-1 with siRNA transfection in A-253 (WISP-1 $\mathrm{Up)}$ cells. Figure $5 \mathrm{C}$ indicates the marked downregulation of WISP-1 mRNA $(P<0.01)$. Moreover, the WISP-1 knockdown also reduced the MMP-2 mRNA level in A-253 (WISP-1 Up) cells $(P<0.05$; Figure 5D). The WISP-1 knockdown and the MMP-2 downregulation were also confirmed at protein levels by the Western blotting assay $(P<0.05$, $P<0.01$, or $P<0.001$; Figure $5 \mathrm{E}$ and $\mathrm{F}$ ). Taken together, we found that WISP-1 promoted the MMP-2 expression in salivary gland A-253 cells.

\section{MMP-2 knockdown inhibits the WISP-I - mediated growth promotion of A-253 cells}

In order to examine the role of MMP-2 in the WISP-1mediated growth promotion of A-253 cells, we knocked 


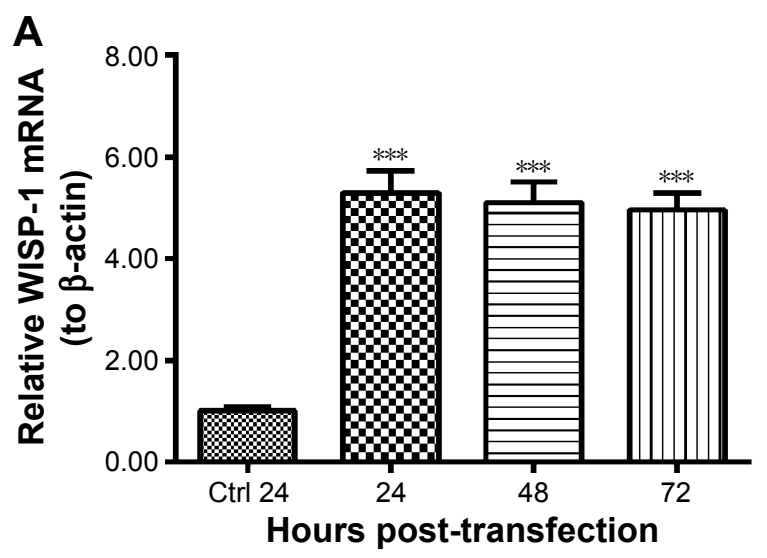

B

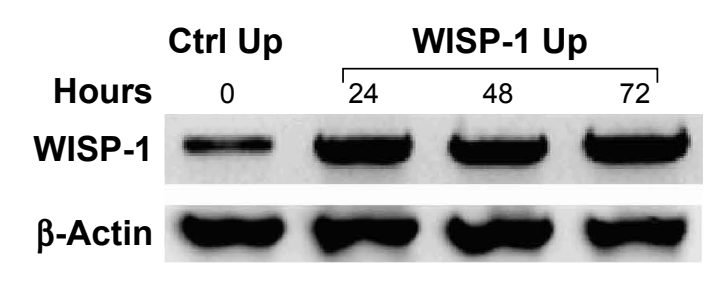

C

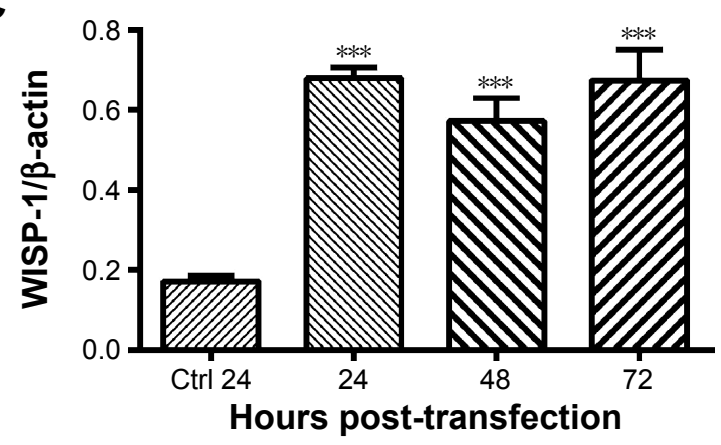

D

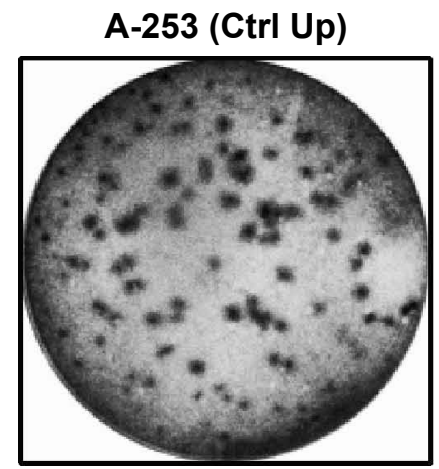

A-253 (WISP-1 Up)

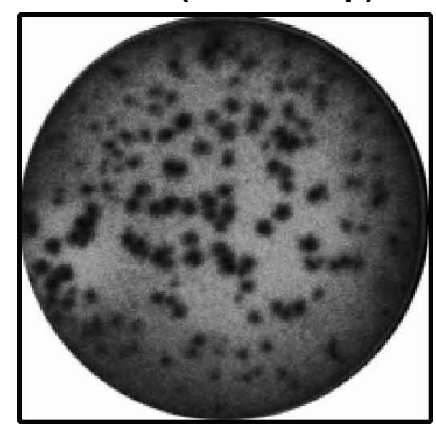

E

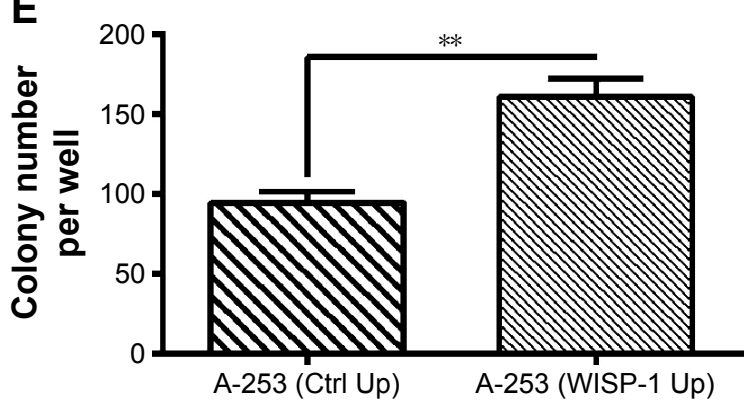

Figure 4 Overexpressed WISP-I promotes the growth of A-253 cells.

Notes: (A) RT-qPCR analysis of the WISP-I mRNA in the A-253 cells, which were transfected with Ctrl-pcDNA3.I (+) plasmid for 24 hours, or with WISP-I-pcDNA3.I (+) plasmid for 24,48 , or 72 hours. (B) Western blotting assay of WISP-I in the Ctrl-pcDNA3.I (+)- or WISP-I-pcDNA3.I (+)-transfected A-253 cells for 24, 48, or 72 hours. (C) WISP-I was presented as a relative level to $\beta$-actin. Colony-forming assay (D) and colony counting (E) for the Ctrl-pcDNA3.I (+)- or WISP-I-pcDNA3.I (+)-transfected A-253 cells for an inoculation of 48 hours. Experiments were performed independently in triplicate. Statistical significance is shown as $* * P<0.01$ and $* * * P<0.00$ I.

Abbreviations: RT-qPCR, real-time quantitative polymerase chain reaction; Ctrl, control.

down MMP-2 and reevaluated the growth of A-253 (WISP-1 Up) cells. Figure 6A confirms the knockdown of MMP-2 at mRNA level in the A-253 (WISP-1 Up) cells after the transfection with 30 or $60 \mathrm{nM}$ siRNA-MMP-2 $(P<0.01$ or $P<0.001)$. Then, the growth curve and the colony formation of A-253 (WISP-1 Up) cells after MMP-2 knockdown were reexamined. Figure $6 \mathrm{~B}$ indicates a reduced growth of the A-253 (WISP-1 Up) cells after the transfection with $60 \mathrm{nM}$ siRNA-WISP-1. There were less colonies in the group of A-253 (WISP-1 Up) cells after MMP-2 knockdown (60 nM) $(P<0.05$; Figure 6C and D). All results indicated that MMP-2 might regulate the WISP-1-mediated growth promotion of A-253 cells.

\section{Discussion}

SGCs represent a group of tumors with morphologically remarkable heterogeneity ${ }^{22}$ and are characterized by locoregional invasion and metastasis. ${ }^{23}$ The heterogeneous cellular make-up poses challenges for the awareness of the tumorigenesis of SGCs, and for the diagnosis and treatment of the carcinoma. Challenge for SGC diagnosis hinders the improvement in SGC prognosis. Several deregulated 
A
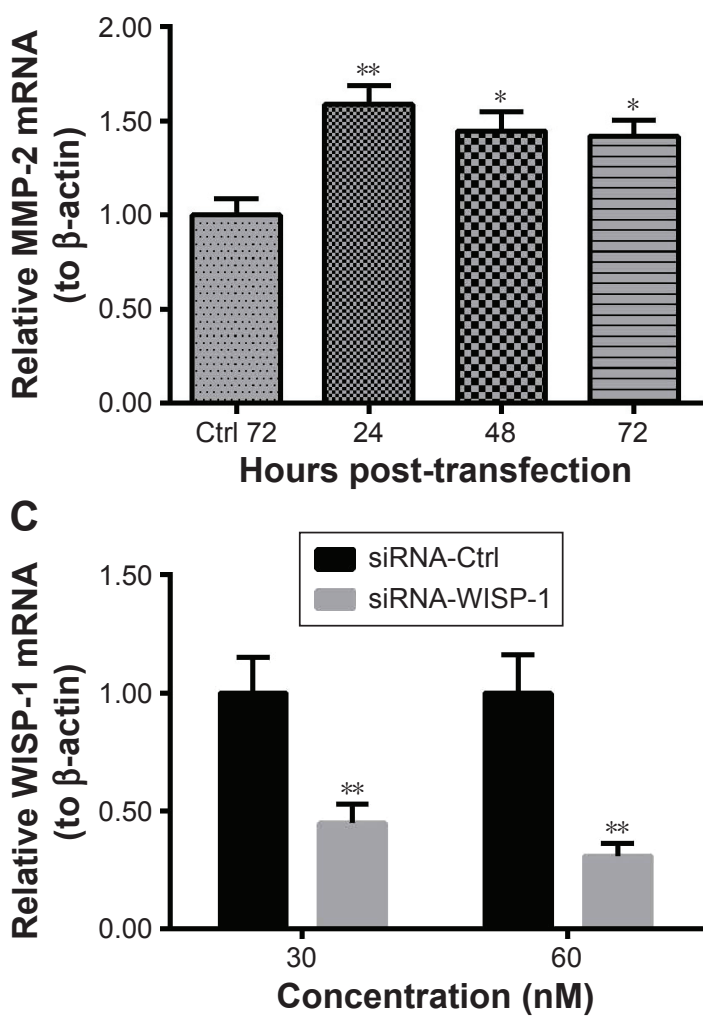

E

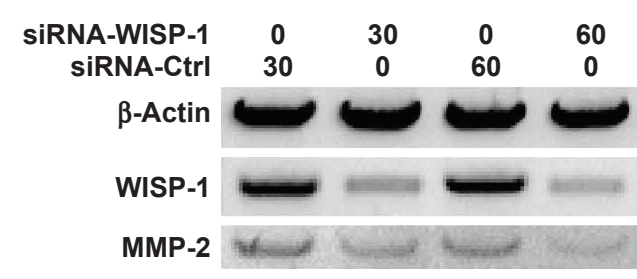

B
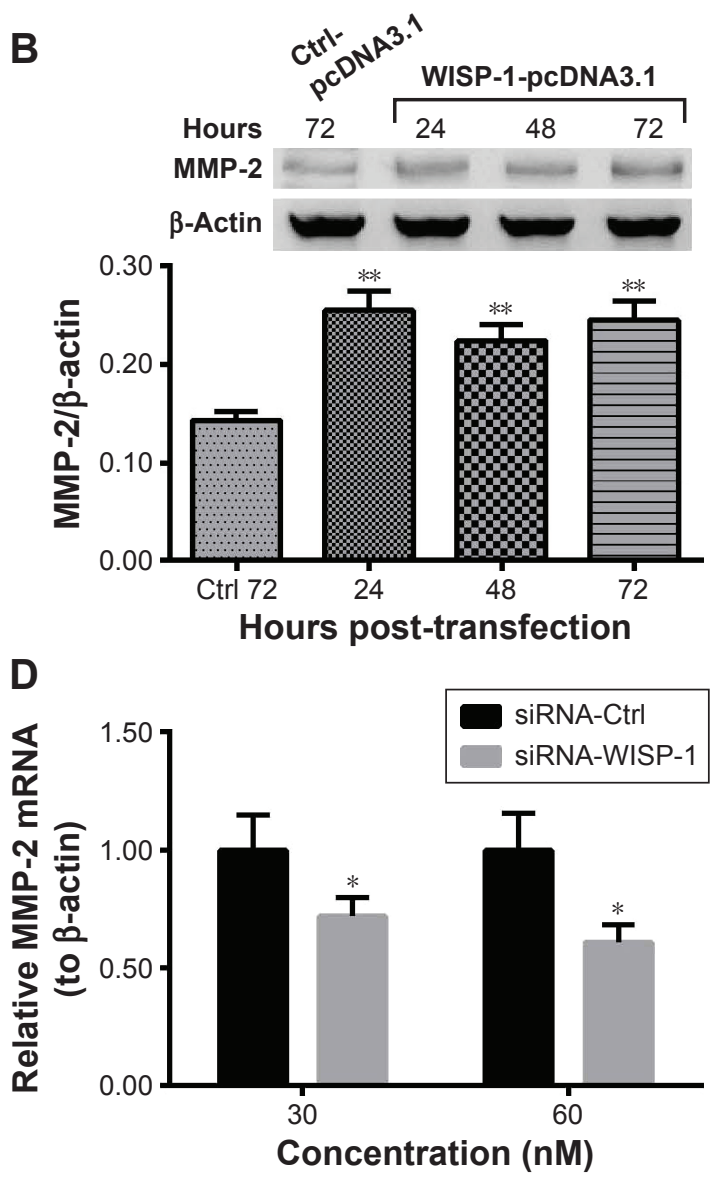

$\mathbf{F}$

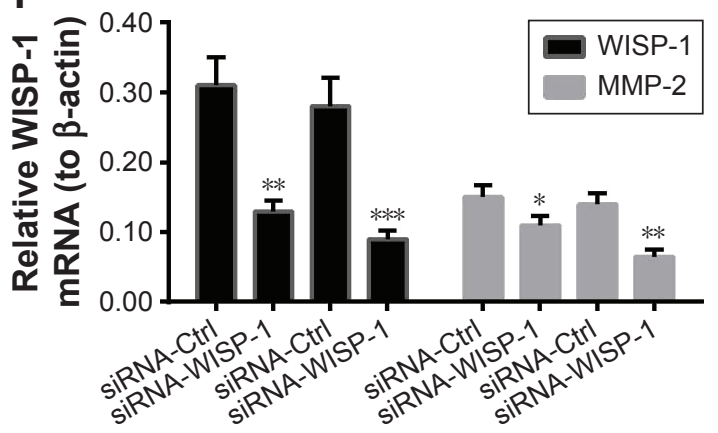

Figure 5 Overexpressed WISP-I upregulates the expression of MMP-2 in A-253 cells.

Notes: (A) RT-qPCR analysis of the MMP-2 mRNA in the A-253 cells, which were transfected with Ctrl-pcDNA3.I (+) plasmid for 24 hours, or with WISP-I-pcDNA3.I(+) plasmid for 24, 48, or 72 hours. (B) Western blotting assay of MMP-2 in the Ctrl-pcDNA3.I(+)- or WISP-I-pcDNA3.I (+)-transfected A-253 cells, at 24, 48, or 72 hours. RT-qPCR analysis of the (C) WISP-I and (D) MMP-2 mRNA in the A-253 cells, which were transfected with 30 or 60 nM siRNA-Ctrl or siRNA-WISP-I for 24 hours. (E) Western blotting assay and (F) quantification of WISP-I and MMP-I in the siRNA-Ctrl- or siRNA-WISP-I-transfected (60 nM) A-253 cells, at 24 , 48 , or 72 hours. The quantitative data were averaged for triple independent results. Statistical significance is shown as $* P<0.05$, $* * P<0.0 \mathrm{I}$, or $* * * P<0.00 \mathrm{I}$.

Abbreviations: RT-qPCR, real-time quantitative polymerase chain reaction; Ctrl, control.

biomarkers have been recognized in SGCs, such as PTTG, TP53, and EGFR, ${ }^{5-8}$ in association with their malignancy. In the present study, we found the WISP-1 overexpression at both mRNA and protein levels in SGC tissues, via various methods, including immunohistochemical staining, Western blotting assay, and RT-qPCR. The WISP-1 overexpression was associated with the lymph node dissection or the bone invasion of SGCs.
Deregulation of WISP-1 has been indicated to correlate with various pathologies including osteoarthritis, fibrosis, and cancer. ${ }^{24}$ Particularly, the impact of WISP-1 has been identified in various types of tumors in processes such as tumor cell proliferation, migration, and survival. ${ }^{25}$ Recombinant WISP-1 has been confirmed to induce the proliferation of alveolar epithelial cells and adenocarcinomic alveolar basal epithelial cells. ${ }^{26}$ Overexpressed WISP-1 has been found to 

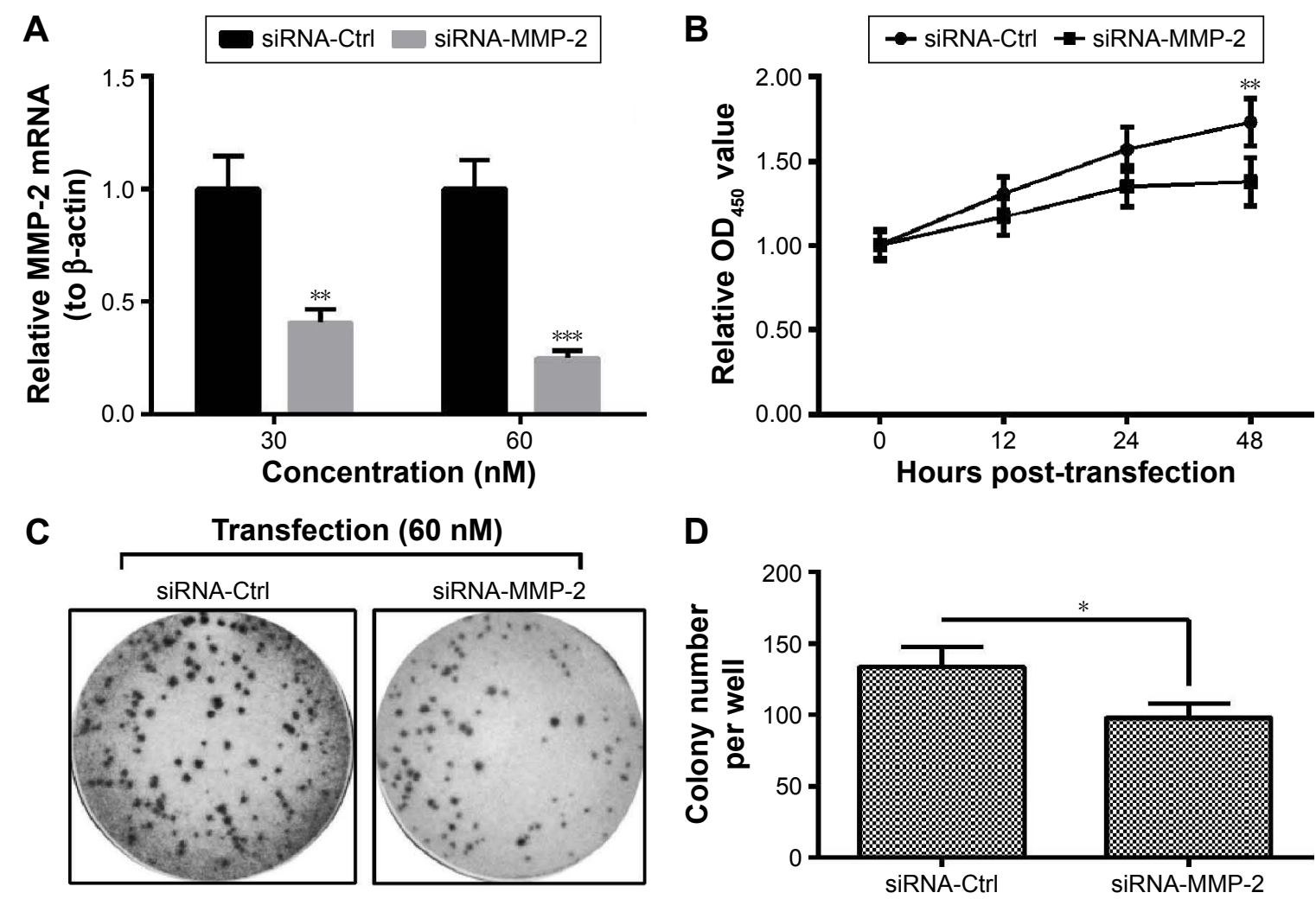

Figure 6 Influence of the MMP-2 knockdown on the growth of A-253 cells.

Notes: (A) RT-qPCR analysis of the MMP-2 mRNA in the A-253 cells, which were transfected with 30 or 60 nM siRNA-Ctrl or siRNA-MMP-2 for 24 hours. (B) CCK-8 assay for the growth curve of the A-253 cells, which were transfected with $60 \mathrm{nM}$ siRNA-Ctrl or siRNA-MMP-2 for 0, 12 , 24, or 48 hours. (C) Colony-forming assay and (D) colony counting for the siRNA-Ctrl- or siRNA-MMP-2-transfected (60 nM) A-253 cells for an inoculation of 48 hours. Experiments were performed independently in triplicate. Statistical significance is shown as $* P<0.05$, $* * P<0.01$, or $* * * P<0.001$.

Abbreviations: RT-qPCR, real-time quantitative polymerase chain reaction; CCK-8, Cell Counting Kit; Ctrl, control.

increase the growth rate of mouse embryonic fibroblasts ${ }^{27}$ and human esophageal cancer cells. ${ }^{28}$ On the other side, WISP-1 has been indicated to be inhibitory to the growth of melanoma cells. ${ }^{29,30}$ The migration and invasion of cells have also been regulated by WISP-1 in gastric carcinoma, ${ }^{27}$ cholangiocarcinoma, ${ }^{21}$ and prostate cancer. ${ }^{31}$ Our study demonstrated that the overexpressed WISP-1 promoted the growth of salivary gland A-253 cells by results of both growth curve and colony-forming assay. Both exogenous WISP-1 treatment and intracellular overexpression of WISP-1 exerted such promotion on the A-253 cell proliferation.

MMPs are a family ( $>20$ members) of zinc-containing enzymes,${ }^{32}$ which play an important role in remodeling of the ECM under physiological situations and in the morphogenesis of salivary glands. ${ }^{33}$ Overexpression of MMPs, particularly MMP-2 or MMP-9, promotes the breakdown of ECM which occurs in many pathological conditions such as proliferation, invasion, and metastasis of cancers. ${ }^{34}$ MMP-2 and MMP-9 have been implicated in the progression, invasion, and metastasis of various types of cancers. ${ }^{35-37}$ MMP-2 expression in particular seems to be related to the invasive properties and the malignant potential of SGCs. ${ }^{33,38,39}$ Moreover, it was indicated that the MMP-2 expression was regulated by WISP-1. ${ }^{21}$ Therefore, we speculated that the WISP-1 overexpression and its promotion of SGC cell proliferation might be mediated by MMP-2. Our results confirmed the upregulation by WISP-1 of the MMP-2 expression in salivary gland A-253 cells. On the other side, the knockdown of WISP-1 reduced the MMP-2 expression in the WISP-1-overexpressed A-253 cells. In addition, the MMP-2 knockdown inhibited the WISP-1-promoted A-253 cell proliferation. However, the association of WISP-1 with other types of MMPs in SGC is not clear. Also, the regulatory role of such association in the SGC progression is not known. This should be explained by further investigations.

\section{Conclusion}

We found that WISP-1 was overexpressed in the human SGCs, and the WISP-1 overexpression promoted the salivary gland cell proliferation and upregulated MMP-2 expression. Moreover, MMP-2 knockdown inhibited the WISP-1-mediated growth promotion of A-253 cells. Our study recognized the 
oncogenic role of WISP-1 in human SGCs, which could serve as a potential target for anticancer therapy.

\section{Acknowledgment}

This study was supported by the postdoc grant from the First Affiliated Hospital of Henan University of Science and Technology (2013-pd023).

\section{Disclosure}

The authors report no conflicts of interest in this work.

\section{References}

1. Landis SH, Murray T, Bolden S, Wingo PA. Cancer statistics, 1999. CA Cancer J Clin. 1999;49(1):8-31, 1.

2. Ettl T, Schwarz-Furlan S, Gosau M, Reichert TE. Salivary gland carcinomas. Oral Maxillofac Surg. 2012;16(3):267-283.

3. Hocwald E, Korkmaz H, Yoo GH, et al. Prognostic factors in major salivary gland cancer. Laryngoscope. 2001;111(8):1434-1439.

4. Speight PM, Barrett AW. Prognostic factors in malignant tumours of the salivary glands. Br J Oral Maxillofac Surg. 2009;47(8):587-593.

5. Etges A, Nunes FD, Ribeiro KC, Araujo VC. Immunohistochemical expression of retinoblastoma pathway proteins in normal salivary glands and in salivary gland tumours. Oral Oncol. 2004;40(3):326-331.

6. Shang J, Shui Y, Sheng L, Wang K, Hu Q, Wei Q. Epidermal growth factor receptor and human epidermal growth receptor 2 expression in parotid mucoepidermoid carcinoma: possible implications for targeted therapy. Oncol Rep. 2008;19(2):435-440.

7. Ettl T, Schwarz S, Kleinsasser N, Hartmann A, Reichert TE, Driemel O. Overexpression of EGFR and absence of C-KIT expression correlate with poor prognosis in salivary gland carcinomas. Histopathology. 2008;53(5):567-577.

8. Liu J, Wang Y, He H, Jin W, Zheng R. Overexpression of the pituitary tumor transforming gene upregulates metastasis in malignant neoplasms of the human salivary glands. Exp Ther Med. 2015;10(2):763-768.

9. Senft E, Lemound J, Stucki-Koch A, Gellrich NC, Kreipe H, Hussein K. Expression of cyclin-dependent kinase inhibitor 2A 16, tumour protein 53 and epidermal growth factor receptor in salivary gland carcinomas is not associated with oncogenic virus infection. Int J Oral Sci. 2015;7(1):18-22.

10. Brigstock DR, Goldschmeding R, Katsube KI, et al. Proposal for a unified CCN nomenclature. Mol Pathol. 2003;56(2):127-128.

11. Brigstock DR. The connective tissue growth factor/cysteine-rich 61/ nephroblastoma overexpressed (CCN) family. Endocr Rev. 1999;20(2): 189-206.

12. Lau LF, Lam SC. The CCN family of angiogenic regulators: the integrin connection. Exp Cell Res. 1999;248(1):44-57.

13. Pennica D, Swanson TA, Welsh JW, et al. WISP genes are members of the connective tissue growth factor family that are up-regulated in wnt-1-transformed cells and aberrantly expressed in human colon tumors. Proc Natl Acad Sci U S A. 1998;95(25):14717-14722.

14. Xu L, Corcoran RB, Welsh JW, Pennica D, Levine AJ. WISP-1 is a Wnt-1- and beta-catenin-responsive oncogene. Genes Dev. 2000;14(5): 585-595.

15. Leask A. Will o' the wisp: $\mathrm{CCN} 4$ as a novel molecular target in osteoarthritis. J Cell Commun Signal. 2011;5(1):51-52.

16. Li X, Chen Y, Ye W, et al. Blockade of CCN4 attenuates CCl4-induced liver fibrosis. Arch Med Sci. 2015;11(3):647-653.

17. Yang JY, Yang MW, Huo YM, et al. High expression of WISP-1 correlates with poor prognosis in pancreatic ductal adenocarcinoma. $\mathrm{Am}$ $J$ Transl Res. 2015;7(9):1621-1628.

18. Chuang JY, Chen PC, Tsao CW, et al. WISP-1 a novel angiogenic regulator of the $\mathrm{CCN}$ family promotes oral squamous cell carcinoma angiogenesis through VEGF-A expression. Oncotarget. 2015;6(6):4239-4252.
19. Livak KJ, Schmittgen TD. Analysis of relative gene expression data using real-time quantitative PCR and the 2(-Delta Delta C(T)) method. Methods. 2001;25(4):402-408.

20. Wu CL, Tsai HC, Chen ZW, et al. Ras activation mediates WISP-1induced increases in cell motility and matrix metalloproteinase expression in human osteosarcoma. Cell Signal. 2013;25(12):2812-2822.

21. Hou CH, Chiang YC, Fong YC, Tang CH. WISP-1 increases MMP-2 expression and cell motility in human chondrosarcoma cells. Biochem Pharmacol. 2011;81(11):1286-1295.

22. Mardani M, Andisheh-Tadbir A, Khademi B, Biparva P, Malekzadeh M. Serum level of matrix metalloproteinase- 9 in patients with salivary gland tumor. J Dent (Shiraz). 2014;15(4):199-203.

23. Lopes MA, Santos GC, Kowalski LP. Multivariate survival analysis of 128 cases of oral cavity minor salivary gland carcinomas. Head Neck. 1998;20(8):699-706.

24. Berschneider B, Konigshoff M. WNT1 inducible signaling pathway protein 1 (WISP1): a novel mediator linking development and disease. Int J Biochem Cell Biol. 2011;43(3):306-309.

25. Gurbuz I, Chiquet-Ehrismann R. CCN4/WISP1 (WNT1 inducible signaling pathway protein 1): a focus on its role in cancer. Int J Biochem Cell Biol. 2015;62:142-146.

26. Konigshoff M, Kramer M, Balsara N, et al. WNT1-inducible signaling protein-1 mediates pulmonary fibrosis in mice and is upregulated in humans with idiopathic pulmonary fibrosis. J Clin Invest. 2009;119(4): 772-787.

27. Tanaka S, Sugimachi K, Saeki H, et al. A novel variant of WISP1 lacking a Von Willebrand type $\mathrm{C}$ module overexpressed in scirrhous gastric carcinoma. Oncogene. 2001;20(39):5525-5532.

28. Nagai $Y$, Watanabe M, Ishikawa S, et al. Clinical significance of Wntinduced secreted protein-1 (WISP-1/CCN4) in esophageal squamous cell carcinoma. Anticancer Res. 2011;31(3):991-997.

29. Hashimoto Y, Shindo-Okada N, Tani M, et al. Expression of the Elm1 gene, a novel gene of the $\mathrm{CCN}$ (connective tissue growth factor, Cyr61/ Cef10, and neuroblastoma overexpressed gene) family, suppresses in vivo tumor growth and metastasis of K-1735 murine melanoma cells. J Exp Med. 1998;187(3):289-296.

30. Shao H, Cai L, Grichnik JM, et al. Activation of Notch1 signaling in stromal fibroblasts inhibits melanoma growth by upregulating WISP-1. Oncogene. 2011;30(42):4316-4326.

31. Ono M, Inkson CA, Sonn R, et al. WISP1/CCN4: a potential target for inhibiting prostate cancer growth and spread to bone. PLoS One. 2013; 8(8):e71709

32. Massova I, Kotra LP, Fridman R, Mobashery S. Matrix metalloproteinases: structures, evolution, and diversification. FASEB J. 1998;12(12): $1075-1095$.

33. Zhang X, Wang Y, Yamamoto G, Tachikawa T. Expression of matrix metalloproteinases MMP-2, MMP-9 and their tissue inhibitors TIMP-1 and TIMP-2 in the epithelium and stroma of salivary gland pleomorphic adenomas. Histopathology. 2009;55(3):250-260.

34. Johansson N, Ahonen M, Kahari VM. Matrix metalloproteinases in tumor invasion. Cell Mol Life Sci. 2000;57(1):5-15.

35. Mook OR, Frederiks WM, Van Noorden CJ. The role of gelatinases in colorectal cancer progression and metastasis. Biochim Biophys Acta. 2004;1705(2):69-89.

36. Gomez DE, Alonso DF, Yoshiji H, Thorgeirsson UP. Tissue inhibitors of metalloproteinases: structure, regulation and biological functions. Eur J Cell Biol. 1997;74(2):111-122.

37. Dano K, Romer J, Nielsen BS, et al. Cancer invasion and tissue remodeling - cooperation of protease systems and cell types. APMIS 1999;107(1):120-127.

38. Kayano K, Shimada T, Shinomiya T, et al. Activation of pro-MMP-2 mediated by MT1-MMP in human salivary gland carcinomas: possible regulation of pro-MMP-2 activation by TIMP-2.J Pathol. 2004;202(4): 403-411.

39. Nagel H, Laskawi R, Wahlers A, Hemmerlein B. Expression of matrix metalloproteinases MMP-2, MMP-9 and their tissue inhibitors TIMP-1, -2 , and -3 in benign and malignant tumours of the salivary gland. Histopathology. 2004;44(3):222-231. 


\section{Publish your work in this journal}

OncoTargets and Therapy is an international, peer-reviewed, open access journal focusing on the pathological basis of all cancers, potential targets for therapy and treatment protocols employed to improve the management of cancer patients. The journal also focuses on the impact of management programs and new therapeutic agents and protocols on

patient perspectives such as quality of life, adherence and satisfaction. The manuscript management system is completely online and includes a very quick and fair peer-review system, which is all easy to use. Visit http://www.dovepress.com/testimonials.php to read real quotes from published authors.

Submit your manuscript here: http://www.dovepress.com/oncotargets-and-therapy-journal 